\title{
Molecular structure and diversity of PBAN/pyrokinin family peptides in ants
}

\section{Man-Yeon Choi * and Robert K. Vander Meer*}

United States Department of Agriculture, Agriculture Research Service, Center for Medical, Agricultural, and Veterinary Entomology, Gainesville, FL, USA

Edited by:

Joe Hull, USDA Agricultural Research

Service, USA

\section{Reviewed by:}

Julang Li, University of Guelph

Canada

Jan Adrianus Veenstra, Universite de

Bordeaux, France

*Correspondence:

Man-Yeon Choi and Robert K. Vander Meer, United States Department of Agriculture, Agriculture Research Service, Center for Medical Agricultural and Veterinary Entomology, 1600 SW 23rd Dr.

Gainesville, FL 32608, USA.

e-mail:mychoi@ars.usda.gov

bob.vandermeer@ars.usda.gov
Neuropeptides are the largest group of insect hormones. They are produced in the central and peripheral nervous systems and affect insect development, reproduction, feeding, and behavior. A variety of neuropeptide families have been identified in insects. One of these families is the PBAN/pyrokinin family defined by a common FXPRLamide or similar amino acid fragment at the C-terminal end. These peptides, found in all insects studied thus far, have been conserved throughout evolution. The most well studied physiological function is regulation of moth sex pheromone biosynthesis through the pheromone biosynthesis activating neuropeptide (PBAN), although several developmental functions have also been reported. Over the past years we have extended knowledge of the PBAN/pyrokinin family of peptides to ants, focusing mainly on the fire ant, Solenopsis invicta. The fire ant is one of the most studied social insects and over the last 60 years a great deal has been learned about many aspects of this ant, including the behaviors and chemistry of pheromone communication. However, virtually nothing is known about the regulation of these pheromone systems. Recently, we demonstrated the presence of PBAN/pyrokinin immunoreactive neurons in the fire ant, and identified and characterized PBAN and additional neuropeptides. We have mapped the fire ant PBAN gene structure and determined the tissue expression level in the central nervous system of the ant. We review here our research to date on the molecular structure and diversity of ant PBAN/pyrokinin peptides in preparation for determining the function of the neuropeptides in ants and other social insects.

Keywords: ant, social insect, PBAN, pyrokinin, neuropeptide, gene structure, diversity

\section{PBAN/PYROKININ PEPTIDES IN INSECTS}

Neuropeptides are part of a large group of neurohormones that have important regulatory functions and are found in most animals. The pheromone biosynthesis activating neuropeptide $(\mathrm{PBAN}) /$ pyrokinin family is a major group of insect neuropeptides, and they are expected to be found in all insect groups, and to have multiple functions during insect development and reproduction. The first peptide identified from the pyrokinin family of peptides was leukopyrokinin from the cockroach, Leucophaea maderae (Holman et al., 1986). Leukopyrokinin has a pyroglutamate at its $\mathrm{N}$-terminal end, and it functions by stimulating the contraction of hindgut muscles in cockroaches, locusts, and crickets (Nachman et al., 1986; Schoofs et al., 1990a,b, 1991; Holman et al., 1991; Predel et al., 1995, 1997; Predel and Nachman, 2001). Independently, the first PBAN was isolated from Helicoverpa zea (Raina et al., 1989), since then many PBAN family peptides have been identified from different insect groups based on their ability to stimulate sex pheromone biosynthesis in moths and/or peptide sequence homology (Rafaeli, 2009; Choi et al., 2010; Jurenka and Rafaeli, 2011).

The PBAN/pyrokinin peptide family is defined by a similar 5-amino-acid C-terminal sequence (ex: FXPRLamide) that is the minimal sequence required for physiological activity (Raina and Kempe, 1990, 1992; Fonagy et al., 1992b; Kuniyoshi et al., 1992).
This motif has been identified in a variety of orders as well as some crustaceans, and has been shown to regulate a variety of insect functions: (1) stimulate pheromone biosynthesis in female moths (Raina et al., 1989); (2) induce melanization in moth larvae (Matsumoto et al., 1990; Altstein et al., 1996); (3) induce embryonic diapause and seasonal polyphenism in moths (Suwan et al., 1994; Uehara et al., 2011); (4) stimulate visceral muscle contraction in cockroaches (Nachman et al., 1986; Predel and Nachman, 2001); (5) accelerate puparium formation in several flies (Zdarek et al., 1997; Verleyen et al., 2004); (6) terminate pupal diapause in heliothine moths (Sun et al., 2003; Xu and Denlinger, 2003). To date, about 200 PBAN/pyrokinin family peptides have been reported from over 40 species (GenBank and unpublished). It is one of the largest neuropeptide families in insects; however, the physiological function of most of these peptides is unknown.

Although a variety of fire ant pheromones have been identified, little is known about the regulation of their production and release. PBAN is synthesized in the subesophageal ganglion (SG), located near the brain $(\mathrm{Br})$, and released into the hemolymph, where it acts on pheromone glands to stimulate pheromone biosynthesis in moths. The mechanism of PBAN control over pheromone production is well understood for sex pheromone biosynthesis in a number of lepidopteran moths (Tillman et al., 1999; Rafaeli, 
2009; Jurenka and Rafaeli, 2011). However, thus far no other insect group has been shown to regulate pheromone biosynthesis using PBAN. PBAN acts directly on pheromone glands by stimulating specific receptor linked G-proteins to open a ligandgated calcium channel to allow the influx of extracellular $\mathrm{Ca}^{2+}$, which is the critical second messenger for PBAN signal transduction (Jurenka et al., 1991, 1994; Fonagy et al., 1992a; Rafaeli and Soroker, 1994; Ma and Roelofs, 1995a; Matsumoto et al., 1995a,b; Choi et al., 2003; Choi and Jurenka, 2004, 2006). Signal transduction is activated quickly once PBAN binds with the specific PBAN receptor (Choi et al., 2003; Hull et al., 2004; Rafaeli et al., 2007; Zheng et al., 2007; Kim et al., 2008; Jurenka and Nusawardani, 2011; Lee et al., 2011). Details of the PBAN mode of action regarding pheromone biosynthesis in moths is reviewed in the regulatory role of PBAN in moths (Jurenka and Rafaeli, 2011).

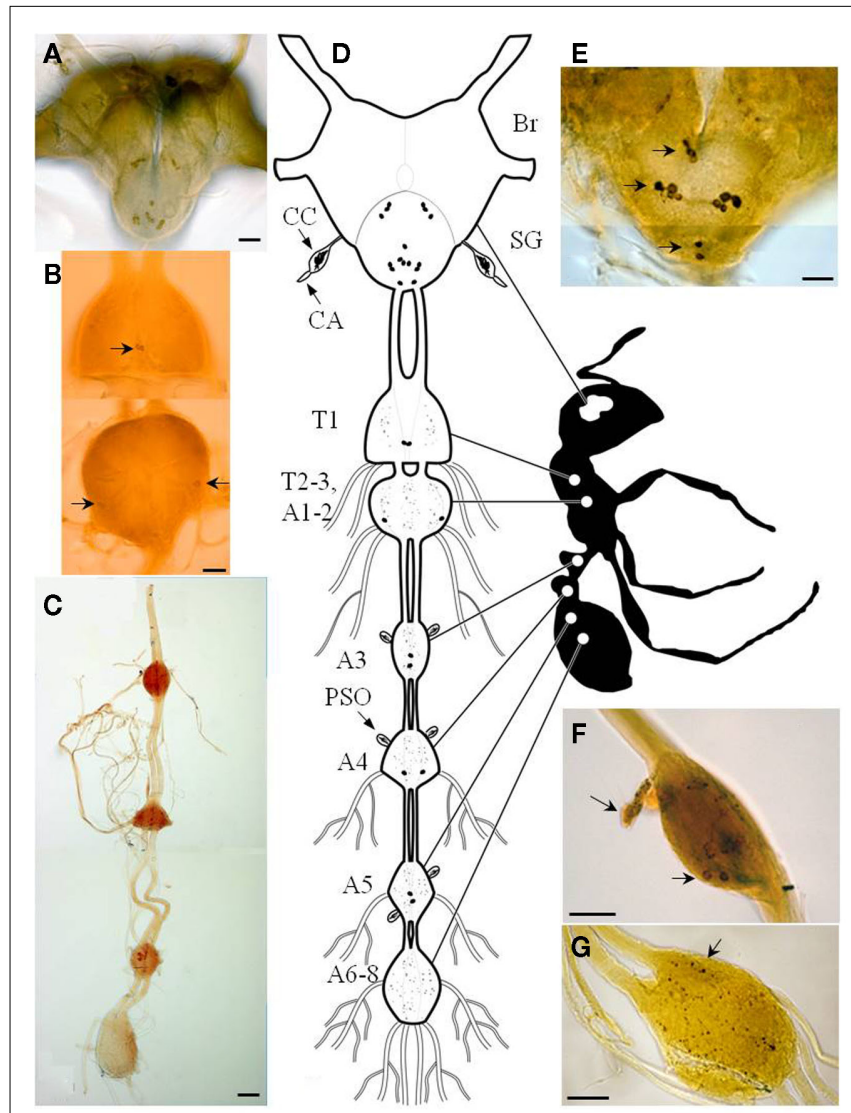

FIGURE 1 | Diagram of the central nervous system of the fire ant adult. Photomicrographs of brain and subesophageal ganglion (A),

immunoreactive neurons in thoracic ganglia [(B), arrows], and abdominal ganglia (C). Schematic drawing of fire ant adult CNS and PBAN-like immunoreactivity (D). Posterior view of an adult Br-SG complex showing somata in the SG and near the esophageal foramen [(E), arrows]. Immunoreactive neurons projecting into perisympathetic organs in abdominal ganglion [(F), arrows]. Terminal ganglion (sixth-eighth neuromeres) containing a densely stained region of varicosities $[(\mathbf{G})$, arrow; $\mathrm{Br}$, brain; SG, subesophageal ganglion; CC, corpora cardiaca; CA, corpora allata; PSO, perisympathetic organ; T1-3, first-third thoracic ganglia; A1-8, first-eight abdominal ganglia]. Bar $=50 \mu \mathrm{m}$ (Choi et al., 2009).

\section{LOCATION OF PBAN/PYROKININ IN ANTS}

Immunocytochemical tools were used to locate PBAN/pyrokinin peptides in the central nervous system (CNS) of the fire ant (Choi et al., 2009). This system visualized PBAN immunoreactivity in dissected $\mathrm{Br}, \mathrm{SG}$, and ventral nerve cord (VNC) of the fire ant (Figure 1). The number and location of PBAN-like immunoreactive neurons showed a similar pattern for all sexual forms and workers (sterile). The distribution pattern of PBANlike immunoreactive materials in the fire ant CNS was similar to that already shown in moths (Blackburn et al., 1992; Kingan et al., 1992; Sato et al., 1994; Ma and Roelofs, 1995b; Davis et al., 1996; Ma et al., 1996; Duportets et al., 1998; Sun et al., 2003; Choi et al., 2004; Wei et al., 2008), locust (Tips et al., 1993), and Drosophila (Choi et al., 2001). However, unlike moths, the last fire ant abdominal ganglion (AG) does not contain PBAN immunoreactive neurons (Figure 1G). Three clusters of neurons were found in the SG (Figures 1A,D,E) and five pairs of neurons in the ventral nervous system (Figures 1B,C,D). The three cell clusters present in the SG are composed of one pair in the most posterior, four pairs in the medial, and three pairs in the anterior ganglia (Figure 1E).

The ganglia in the VNC contained five pairs of PBAN-like immunoreactive neurons (Figures 1B-D). One pair was located in the first thoracic ganglion, and another pair in the second thoracic ganglion (Figure 1B). Neurites along the midline and lateral side

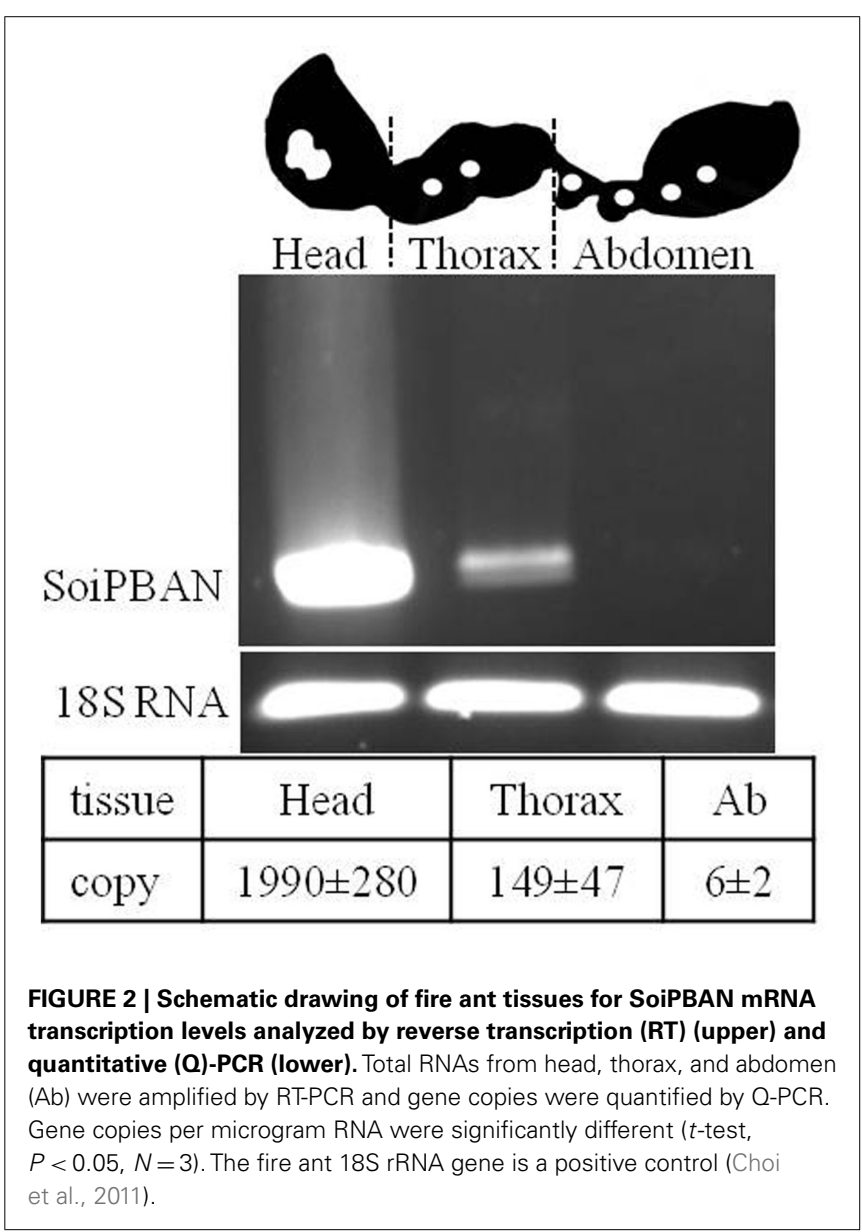


in the thoracic ganglion appeared to descend to the abdominal ganglia (AGs; Figures 1B-D). The other three pairs of neurons exhibiting PBAN-like immunoreactivity were found in the third, fourth, and fifth AGs where the neurons were associated with a distended neurohemal organ (presumably a perisympathetic organ, PSO) located on the surface of each ganglion (Figure 1F). However, there were no neurons with PBAN-like immunoreactive material in the fused terminal AG (A6-A8). A network of neurite varicosities descended from the somata of the fifth AG (Figure 1G). The immunoreactive material in the last ganglion (arrow in Figure 1G) could have traveled from the fifth ganglion or from the SG for release into hemolymph through the neurohemal organs. The origin of this immunoreactive material remains to be determined.

The VNC in ancestral insects has been shown to consist of eight discrete AGs. In evolutionarily advanced insects, the number of AGs varies. In most cases, the first abdominal and/or the terminal AGs are fused with one or more neuromeres; therefore, the number of discrete ganglia is reduced (Niven et al., 2008). The ventral nerve structure of fire ant female alates and queens shows only two thoracic and four AGs. The pro-thoracic ganglion (T1) is discrete, but the meso- (T2), and meta- (T3) thoracic ganglia, and the first (A1) and second (A2) AGs are fused together to form the second structurally discrete thoracic ganglia, as found in most insects. Of the four discrete AGs, A3, A4, and A5 are distinct ganglia; however, the last three AGs (A6, A7, A8) are likely fused forming the single terminal ganglion in the fire ant. A similar fusion pattern for both thoracic and abdominal neuromeres in the VNC has been shown in lepidopteran and hymenopteran species (Niven et al., 2008).

\section{PBAN GENE EXPRESSION IN THE ANT CNS}

Recently, the results for SoiPBAN (Solenopsis invicta PBAN) mRNA expression levels in different tissues of fire ants (Choi et al., 2011) contradicted the strong PBAN immunoreactivity detected in the fire ant VNC (Choi et al., 2009). As anticipated, the strongest transcriptional signal and maximum number of SoiPBAN gene copies were detected in the head (Figure 2), indicating that the gene products including PBAN are actively produced in the SG as shown in Figure 1. SoiPBAN gene transcription and copies in the thoracic tissue were relatively low. However, only a minimal level of PBAN gene transcription was observed in abdominal tissue (Figure 2), in contrast to the strong PBAN-like immunoreactivity observed from abdominal neurons associated with the PSO in the AG (Figure 1). If these peptides were only from SoiPBAN gene products, then gene expression and copy number in abdominal tissue would be expected to be at least similar to or higher than the thorax tissue. Therefore, these results suggest that a FXPRL peptide is dominantly expressed in the abdomen that is derived from a gene other than the SoiPBAN gene. Thus far, only two gene families are known to produce FXPRL peptides: PBAN and the capability (CAPA) genes in insects. PBAN (-DH) genes produce four or five FXPRL or similar sequenced peptides including PBAN and the diapause hormone (DH). The CAPA gene encodes one FXPRL neuropeptide with a very conserved motif, WFGPRL at the C-termini (Predel and Wegener, 2006).

PBAN anti-sera reacts with any C-terminus FXPRL peptide sequence regardless of what gene is producing the peptide, thus the cross-reactivity does not allow the determination of the number genes responsible for the observed reactivity. Interestingly, the
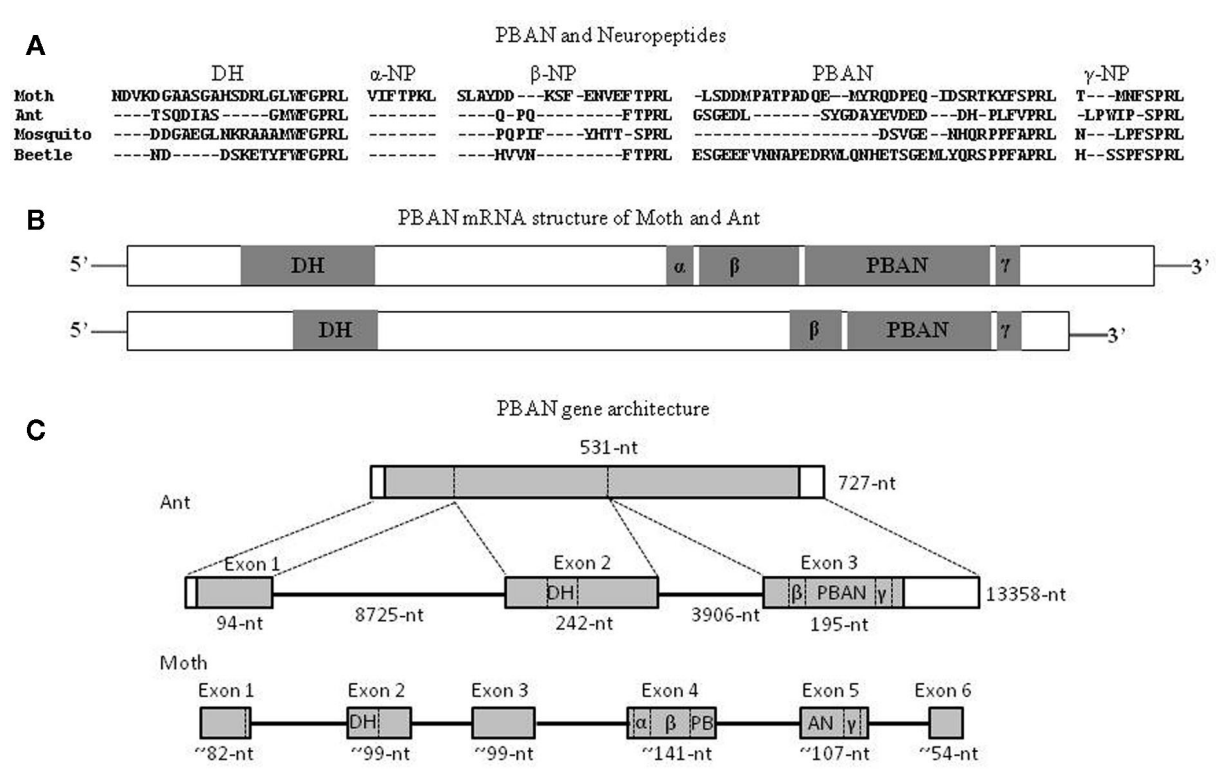

FIGURE 3 | Comparison of amino acid sequences of PBAN and neuropeptides expected from PBAN mRNA of the moth ( $H$. zea), ant ( $S$. invicta), mosquito (A. gambiae), and beetle (T. castaneum) (A), schematic diagram of PBAN-DH mRNA (B), and gene architecture (C). The nucleotide numbers of each exon in lepidopteran PBAN represent means of three moth species. $\mathrm{DH}$, diapause hormone homolog; $\alpha, \beta$, and $\gamma$ : neuropeptides encoded from the cDNA; PBANs are translated from exon 3 in ants, and exons 4 and 5 in moths, respectively. The shaded area represents PBAN coding regions. Open areas represent untranslated regions. The alignment was made with Genetyx-Tree software (ver. 10; Choi and Vander Meer, 2009; Choi et al., 2011). 


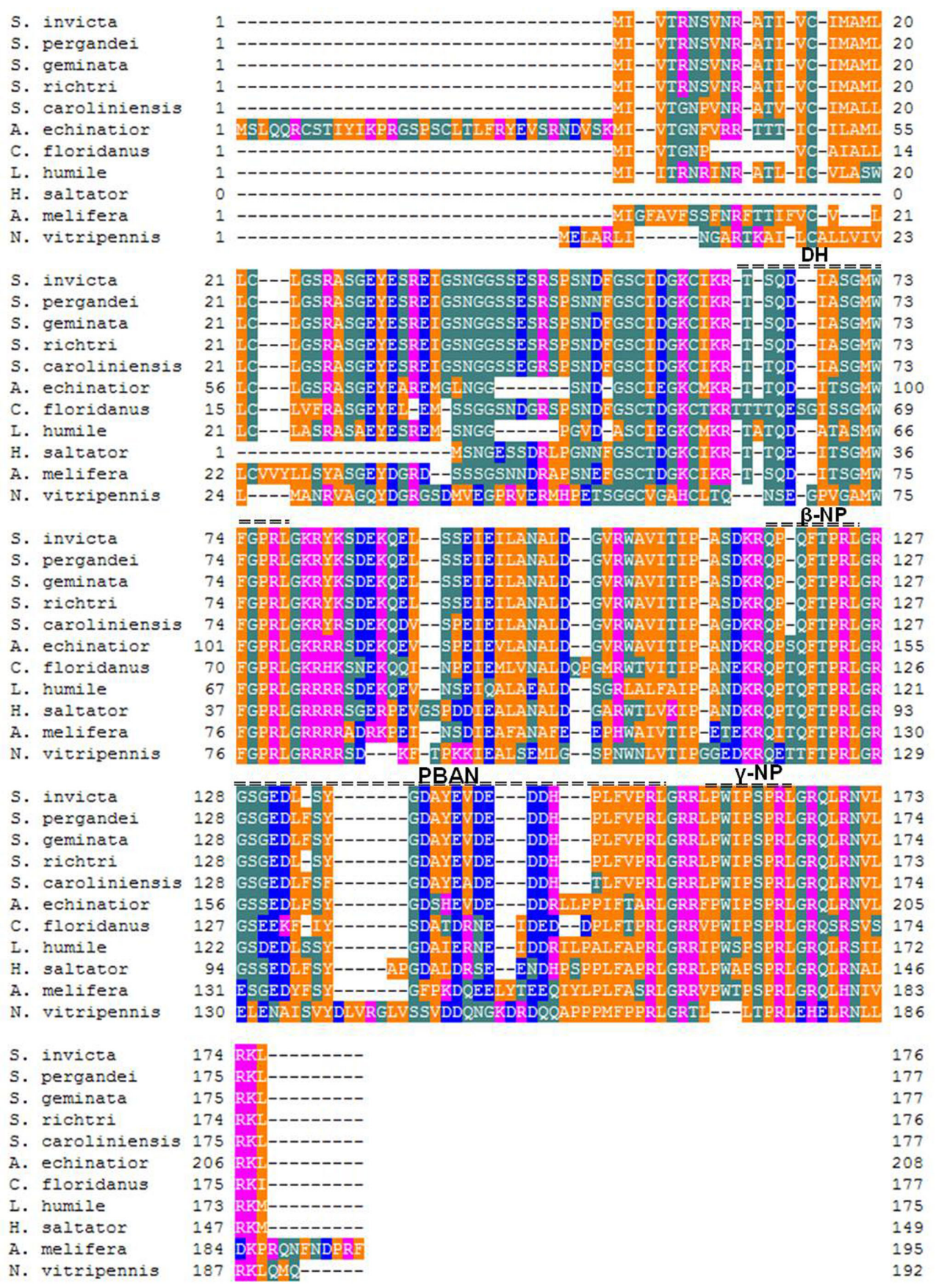

FIGURE 4 | Alignment of PBAN/pyrokinin peptides for hymenopteran insects. The species names are follow: ants (Solenopsis invicta, S. pergandei, S. geminate, S. richteri, S. carolinensis, Acromyrmex echinatior, Camponotus floridanus, Linepithema humile,

immunocytochemistry and the transcription studies strongly suggest that PBAN/pyrokinin-like peptides are encoded from both PBAN/pyrokinin and CAPA genes. Many FXPRL peptides encoded from the CAPA gene have been isolated from the abdominal neurohemal organs of several insect groups (Predel and Wegener, 2006). Recently, we identified a fire ant specific CAPA gene and Harpegnathos saltator), honeybee (Apis melifera), and wasp (Nasonia vitripennis). The alignment was made with Genetyx-Tree software (ver. 10). The translated peptide domains are indicated by double dashes above the aligned sequences. (unpublished data). Though PBAN/pyrokinin family peptides, characterized by the conserved penta-peptide at the C-terminus, have been found independently in various insect groups, it is clear that the PBAN gene is well conserved in Insecta, and probably extends to the entire Arthropod phylum (Neupert et al., 2009). 


\section{MOLECULAR STRUCTURE OF ANT PBANs}

The first ant PBAN was identified from the fire ant, S. invicta, and specifically named SoiPBAN (Choi and Vander Meer, 2009), subsequently four additional PBAN genes were reported from the fire ant species complex (Choi et al., 2010). SoiPBAN cDNA contains 531 nucleotides covering the entire open reading frame (ORF) and encoding 176-amino acids (AA), including four FXPRL-NH $\mathrm{N}_{2}$ peptide domains. The structures of the four FXPRL peptides and their homology with the known insect PBAN/pyrokinin peptides are: (1) $\mathrm{DH}=15-\mathrm{AA}$ (TSQDIASGMWFGPRL-NH ${ }_{2}$ ); (2) $\beta$-neuropeptide $=8$-AA $\left(\right.$ QPQFTPRL- $\left.\mathrm{NH}_{2}\right) ;(3) \mathrm{PBAN}=26$ AA (GSGEDLSYGDAYEVDED DHPLFVPRL- $\mathrm{NH}_{2}$ ); and (4) $\gamma$-neuropeptide $(\mathrm{NP})=9$-AA (LPWIPSPRL- $\mathrm{NH}_{2}$; Figure 3A). Unlike the five peptides, $\mathrm{DH}, \alpha, \beta, \mathrm{PBAN}$, and NPs, encoded from PBAN genes of lepidopteran moths, the domain of $\alpha$-NP is not present in the PBAN genes of ants, mosquitoes, or beetles based on peptide homology (Figures 3A,B). Although C-terminal pentapeptide sequences are slightly different from moths, all four peptides from SoiPBAN cDNA induced inappropriate sex pheromone biosynthesis in H. zea females (Choi and Vander Meer, 2009).

The entire S. invicta PBAN gene (Choi et al., 2011) is composed of 13,358 nucleotides (Figure 3C). The gene is comprised of three exons (94, 242, and 195 nucleotides translated, respectively) interrupted by two large intron gaps; intron 1 and 2. SoiPBAN cDNA encodes a DH-homolog peptide, which is translated from the second exon, and the other peptides, $\beta$-NP, $\gamma$-NP, and SoiPBAN, are translated from the third exon. The ant PBAN gene has three exons and relatively large intron gaps compared to moth PBAN genes that consist of six exons (Xu et al., 1999; Zhang et al., 2005; Jing et al., 2007). A search of two hymenopteran species, Apis mellifera (accession No: NP_001104182) and Nasonia vitripennis (accession No: NP_001161197) genomic DNAs from the NCBI database revealed that these PBAN genes are also composed of three exons as in the fire ant PBAN gene, but contrary to the fire ant PBAN gene they contain very short intron sequence gaps. A comparison of hymenopteran and lepidopteran PBAN genes suggests that exon 1 for both translates the signal peptide. The hymenopteran exon 2 and 3 corresponds to moth PBAN gene exons 2-3 and exons 4-6, respectively (Figure 3C).

\section{MOLECULAR DIVERSITY OF ANT PBANs}

The Solenopsis group is a large genus with 185 described species (Pitts et al., 2005). The genus is difficult taxonomically due to the lack of reliable diagnostic characters. Most recently they have been re-classified into four complexes: S. virulens, S. tridens, S. geminata, and S. saevissima (Pitts et al., 2005). Since the elucidation of the first ant PBAN gene (Choi and Vander Meer, 2009), PBAN genes from four additional Solenopsis species and a hybrid were identified: S. richteri and a S. invicta/S. richteri hybrid (Saevissima complex), S. geminata (Geminata complex), S. pergandei, and S. carolinensis (members of a large group classified as thief ants that live primarily underground; Choi et al., 2010). Solenopsis PBAN genes were divided into two groups of cDNAs translating 176-AA for S. invicta, S. richteri, and the hybrid, and 177-AA for S. geminata, S. pergandei, and S. carolinenesis (Figure 4). The one additional amino acid residue (F) in the later group was associated with the PBAN domain. Comparison of the five fire ant PBAN/pyrokinin genes showed that $S$. carolinensis was the

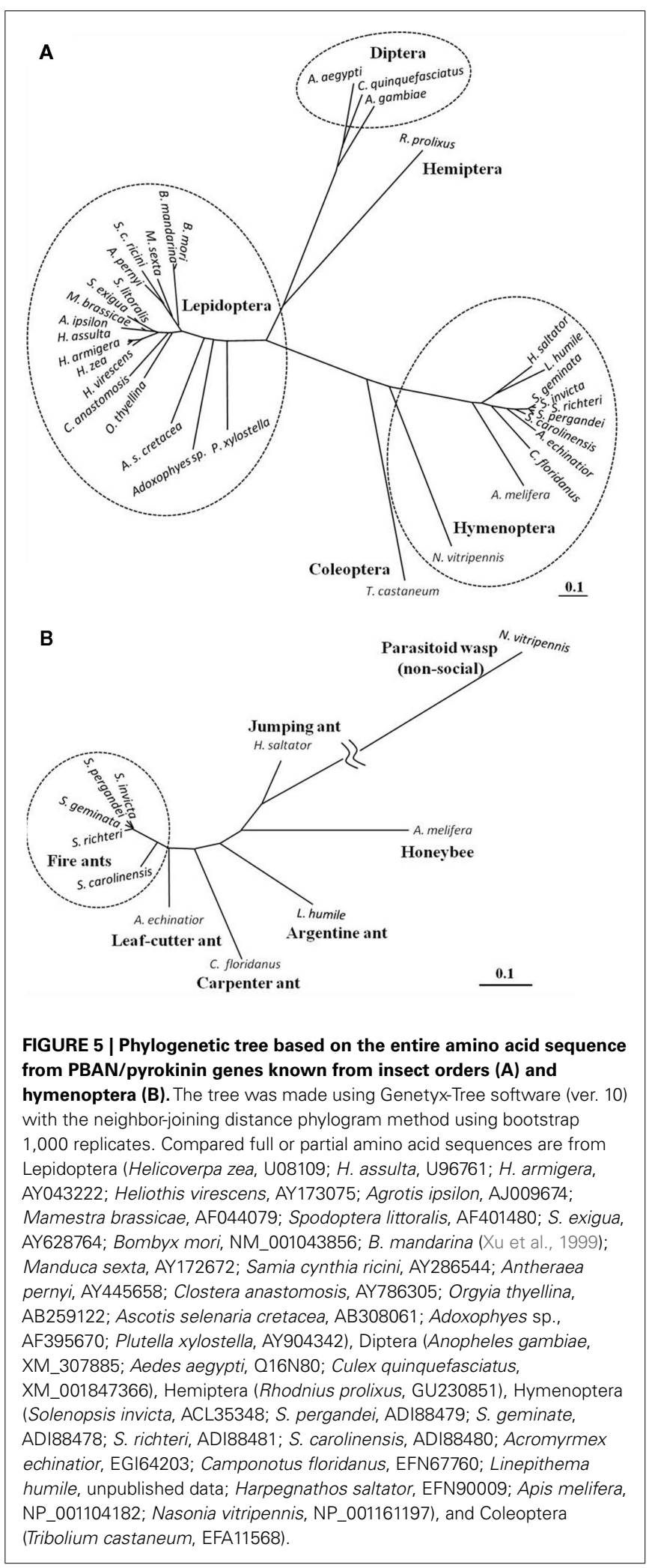

most distant from the other species based on nucleotide sequence homology (Figures 4 and 5B). This phylogenetic classification by neuropeptide sequence is consistent with the morphological cladistic analysis of the Solenopsis genus (Pitts et al., 2005), except 
that S. pergandei most closely resembled S. geminata, and both were very distant from $S$. carolinensis, indicating significant evolutionary distance between the two thief ant species (Figure 5B). Although the PBAN gene products, neuropeptides, are not characterized functionally except for lepidopteran moths, the phylogenic relationship of all known PBAN genes is similar to the taxonomic phylogeny based on the family level of classification and evolutionary tree of Insecta (Figure 5A). This indicates that neuropeptide gene sequences can be used to infer insect phylogenetic relationships. As anticipated, ant PBAN genes are similar within hymenopteran insects, but are distant from moth and mosquito species. Interestingly, if amino acid sequences of PBAN genes are compared in hymenopteran species, the non-social parasitoid wasp, $N$. vitripennis, is very distant from social insects including the honeybee (Figures 4 and 5B). Based on the amino acid sequences translated from PBAN genes from insects, the similarity is correlated with the basic taxonomic or phylogenetic classification of Insecta. The PBAN/pyrokinin gene is well conserved in Insecta, however, the translated pre-propeptides might vary with functional diversity, being retained or lost during the evolutionary process.

\section{FUTURE DIRECTION}

Although the amino acid sequences, gene transcription, and specific neuronal sites for ant PBAN/pyrokinin family peptides are

\section{REFERENCES}

Altstein, M., Gazit, Y., Aziz, O. B., Gabay, T., Marcus, R., Vogel, Z., and Barg, J. (1996). Induction of cuticular melanization in Spodoptera littoralis larvae by PBAN/MRCH: development of a quantitative bioassay and structure function analysis. Arch. Insect Biochem. Physiol. 31, 355-370.

Blackburn, M. B., Kingan, T. G., Raina, A. K., and Ma, M. C. (1992). Colocalization and differential expression of PBAN- and FMRFamidelike immunoreactivity in the subesophageal ganglion of Helicoverpa $z e a$ (Lepidoptera: Noctuidae) during development. Arch. Insect Biochem. Physiol. 21, 225-238.

Choi, M. Y., Fuerst, E. J., Rafaeli, A., and Jurenka, R. (2003). Identification of a $\mathrm{G}$ protein-coupled receptor for pheromone biosynthesis activating neuropeptide from pheromone glands of the moth Helicoverpa zea. Proc. Natl. Acad. Sci. U.S.A. 100, 9721-9726.

Choi, M. Y., and Jurenka, R. A. (2004). PBAN stimulation of pheromone biosynthesis by inducing calcium influx in pheromone glands of Helicoverpa zea. J. Insect Physiol. 50, 555-560.

Choi, M. Y., and Jurenka, R. A. (2006). Role of extracellular $\mathrm{Ca}^{2+}$ and calcium channel activated by a $\mathrm{G}$

now known, their function in ants remains to be determined. The well documented fire ant could be an excellent social insect model to find a specific role of these neuropeptides during immature development, as well as in adult castes. To clarify specific physiological modes of action of PBAN/pyrokinin peptides in the fire ant the identification and characterization of specific receptor(s) for these peptides is required. The study includes measurement of binding activity of PBAN and other peptides to the PBAN receptor expressed in an in vitro system, and determination of the receptor location, e.g., tissue, gland, or organ, which would suggest a potential target site and role for PBAN/pyrokinin peptides. PBAN/pyrokinin peptides have been reported and/or identified from all insect orders investigated so far, thus these neuropeptides including PBAN are expected to have both general and specific roles, such as feeding, diapause, regulation of pheromone production, and/or other endocrinal functions. The work reviewed here lays the groundwork necessary for successfully determination of these functions, which will add significantly to our understanding of development, reproduction and social behavior in ants, and may lead to novel control possibilities for economical important invasive ants.

\section{ACKNOWLEDGMENTS}

We thank Drs. S. Allan and M. Coy for valuable comments to an earlier version.

diversity of PBAN family peptides

pheromone production in Helicoverpa zea (Lepidoptera: Noctuidae). Ann. Entomol. Soc. Am. 99, 905-909. Choi, M. Y., Lee, J. M., Han, K. S., and Boo, K. S. (2004). Identification of a new member of PBAN family and immunoreactivity in the central nervous system from Adoxophyes sp. (Lepidoptera: Tortricidae). Insect Biochem. Mol. Biol. 34, 927-935.

Choi, M. Y., Meer, R. K., Shoemaker, D., and Valles, S. M. (2011). PBAN gene architecture and expression in the fire ant, Solenopsis invicta. J. Insect Physiol. 57, 161-165.

Choi, M. Y., Rafaeli, A., and Jurenka, R. A. (2001). Pyrokinin/PBAN-like peptides in the central nervous system of Drosophila melanogaster. Cell Tissue Res. 306, 459-465.

Choi, M. Y., Raina, A., and Vander Meer, R. K. (2009). PBAN/pyrokinin peptides in the central nervous system of the fire ant, Solenopsis invicta. Cell Tissue Res. 335, 431-439.

Choi, M. Y., and Vander Meer, R. K. (2009). Identification of a new member of the PBAN family of neuropeptides from the fire ant, Solenopsis invicta. Insect Mol. Biol. 18, 161-169.

Choi, M. Y., Vander Meer, R. K., and Valles, S. M. (2010). Molecular from fire ants. Arch. Insect Biochem. Physiol. 74, 67-80.

Holman, G. M., Cook, B. J., and Nachman, R. J. (1986). Isolation, primary structure and synthesis of a blocked neuropeptide isolated from the cockroach, Leucophaea maderae. Comp. Biochem. Physiol. 85C, 219-224.

Holman, G. M., Nachman, R. J., Schoofs, L., Hayes, T. K., Wright, M. S., and De Loof, A. (1991). The Leucophaea maderae hindgut preparation: a rapid and sensitive bioassay tool for the isolation of insect myotropins of other insect species. Insect Biochem. 21, $107-112$.

Duportets, L., Gadenne, C., Dufour, M. C., and Couillaud, F. (1998). The pheromone biosynthesis activating neuropeptide (PBAN) of the black cutworm moth, Agrotis ipsilon: immunohistochemistry, molecular characterization and bioassay of its peptide sequence. Insect Biochem. Mol. Biol. 28, 591-599.

Fonagy, A., Matsumoto, S., Uchhiumi, K., and Mitsui, T. (1992a). Role of calcium ion and cyclic nucleotides in pheromone production in Bombyx mori. J. Pest. Sci 17, 115-121.

Fonagy, A., Schoofs, L., Matsumoto, S., De Loof, A., and Mitsui, T. (1992b). Functional cross-reactivities of some locustamyotropins and Bombyx pheromone biosynthesis activating neuropeptide. J. Insect Physiol. 38, 651-657.
Hull, J. J., Ohnishi, A., Moto, K., Kawasaki, Y., Kurata, R., Suzuki, M. G., and Matsumoto, S. (2004). Cloning and characterization of the pheromone biosynthesis activating neuropeptide receptor from the silkmoth, Bombyx mori. Significance of the carboxyl terminus in receptor internalization. J. Biol. Chem. 279, 51500-51507.

Jing, T. Z., Wang, Z. Y., Qi, F. H., and Liu, K. Y. (2007). Molecular characterization of diapause hormone and pheromone biosynthesis activating neuropeptide from the black-back prominent moth, Clostera anastomosis (L.) (Lepidoptera, Notodontidae). Insect Biochem. Mol. Biol. 37, 1262-1271. 
Jurenka, R., and Nusawardani, T. (2011). The pyrokinin/pheromone biosynthesis-activating neuropeptide (PBAN) family of peptides and their receptors in Insecta: evolutionary trace indicates potential receptor ligand-binding domains. Insect Mol. Biol. 20, 323-334.

Jurenka, R., and Rafaeli, A. (2011). Regulatory role of PBAN in sex pheromone biosynthesis of heliothine moths. Front. Exp. Endocrinol. 2:46, 1-8.

Jurenka, R. A., Fabrias, G., Devoe, L., and Roelofs, W. L. (1994). Action of PBAN and related peptides on pheromone biosynthesis in isolated pheromone glands of the redbanded leafroller moth, Argyrotaenia velutinana. Comp. Biochem. Physiol. Pharmacol. Toxicol. Endocrinol. 108, 153-160.

Jurenka, R. A., Jacquin, E., and Roelofs, W. L. (1991). Stimulation of pheromone biosynthesis in the moth Helicoverpa zea: action of a brain hormone on pheromone glands involves $\mathrm{Ca}^{2+}$ and cAMP as second messengers. Proc. Natl. Acad. Sci. U.S.A. 88, 8621-8625.

Kim, Y. J., Nachman, R. J., Aimanova, K., Gill, S., and Adams, M. E. (2008). The pheromone biosynthesis activating neuropeptide (PBAN) receptor of Heliothis virescens: identification, functional expression, and structure-activity relationships of ligand analogs. Peptides 29, 268-275.

Kingan, T. G., Blackburn, M. B., and Raina, A. (1992). The identification of pheromone-biosynthesisactivating neuropeptide (PBAN) immunoreactivity in the central nervous system of the corn earworm, Helicoverpa zea. Cell Tissue Res. 270, 229-240.

Kuniyoshi, H., Nagasawa, H., Ando, T., Suzuki, A., Nachman, R. J., and Holman, G. M. (1992). Cross-activity between pheromone biosynthesis activating neuropeptide (PBAN) and myotropic pyrokinin insect peptides. Biosci. Biotechnol. Biochem. 56, 167-168.

Lee, D. W., Shrestha, S., Kim, A. Y., Park, S. J., Yang, C. Y., Kim, Y., and Koh, Y. H. (2011). RNA interference of pheromone biosynthesis-activating neuropeptide receptor suppresses mating behavior by inhibiting sex pheromone production in Plutella xylostella (L.). Insect Biochem. Mol. Biol. 41, 236-243.

Ma, P. W. K., and Roelofs, W. L. (1995a). Calcium involvement in the stimulation of sex pheromone production by PBAN in the European corn borer, Ostrinia nubilalis (Lepidoptera: Pyralidae). Insect Biochem. Mol. Biol. 25, 467-473.

Ma, P. W. K., and Roelofs, W. L. (1995b). Sites of synthesis and release of PBAN-like factor in the female European corn borer, Ostrinia nubilalis. J. Insect Physiol. 41, 339-350.

Ma, P. W. K., Roelofs, W. L., and Jurenka, R. A. (1996). Characterization of PBAN and PBAN-encoding gene neuropeptides in the central nervous system of corn earworm moth, Helicoverpa zea. J. Insect Physiol. 42, 257-266.

Matsumoto, S., Kitamura, A., Nagasawa, H., Kataoka, H., Orikasa, C., Mitsui, T., and Suzuki, A. (1990). Functional diversity of a neurohormone produced by the suboesophageal ganglion: molecular identity of melanization and reddish colouration hormone and pheromone biosynthesis activating neuropeptide. J. Insect Physiol. 36, 427-432.

Matsumoto, S., Ozawa, R., Nagamine, T., Kim, G. H., Uchiumi, K., Shono, T., and Mitsui, T. (1995a). Intracellular transduction in the regulation of pheromone biosynthesis of the silkworm, Bombyx mori: suggested involvement of calmodulin and phosphoprotein phosphatase. Biosci. Biotechnol. Biochem. 59, 560-562.

Matsumoto, S., Ozawa, R., Uchiumi, K., Kurihara, M., and Mitsui, T. (1995b). Intracellular signal transduction of PBAN action in the common cutworm, Spodoptera litura: effects of pharmacological agents on sex pheromone production in vitro. Insect Biochem. Mol. Biol. 25, 1055-1059.

Nachman, R. J., Holman, G. M., and Cook, B. J. (1986). Active fragments and analogs of the insect neuropeptide Leucopyrokinin: structure-function studies. Biochem. Biophys. Res. Commun. 137, 936-942.

Neupert, S., Russell, W. K., Predel, R., Russell, D. H., Strey, O. F., Teel, P. D., and Nachman, R. J. (2009). The neuropeptidomics of Ixodes scapularis synganglion. J. Proteomics 72, 1040-1045.

Niven, J. E., Graham, C. M., and Burrows, M. (2008). Diversity and evolution of the insect ventral nerve cord. Annu. Rev. Entomol. 53, 253-271.

Pitts, J. P., Mchugh, J. V., and Ross, K. G. (2005). Cladistic analysis of the fire ants of the Solenopsis saevissima species-group (Hymenoptera: Formicidae). Zool. Scr. 34, 493-505.

Predel, R., Kellner, R., Kaufmann, R., Penzlin, H., and Gade, G. (1997). Isolation and structural elucidation of two pyrokinins from the retrocerebral complex of the American cockroach. Peptides 18, 473-478.

Predel, R., Linde, D., Rapus, J., Vettermann, S., and Penzlin, H. (1995) Periviscerokinin (Pea-PVK): a novel myotropic neuropeptide from the perisympathetic organs of the American cockroach. Peptides 16, 61-66.

Predel, R., and Nachman, R. J. (2001). Efficacy of native FXPRLamides (pyrokinins) and synthetic analogs on visceral muscles of the American cockroach. J. Insect Physiol. 47, 287-293.

Predel, R., and Wegener, C. (2006). Biology of the CAPA peptides in insects. Cell. Mol. Life Sci. 63, 2477-2490.

Rafaeli, A. (2009). Pheromone biosynthesis activating neuropeptide (PBAN): regulatory role and mode of action. Gen. Comp. Endocrinol. 162, 69-78.

Rafaeli, A., Bober, R., Becker, L., Choi, M. Y., Fuerst, E. J., and Jurenka, R. (2007). Spatial distribution and differential expression of the PBAN receptor in tissues of adult Helicoverpa spp. (Lepidoptera: Noctuidae). Insect Mol. Biol. 16, 287-293.

Rafaeli, A., and Soroker, V. (1994). "Second messenger interactions in response to PBAN stimulation of pheromone gland cultures," in Insect Neurochemistry and Neurophysiology, eds A. Borkovec and M. J. Loeb (Boca Raton, FL: CRC Press), 223-226.

Raina, A. K., Jaffe, H., Kempe, T. G., Keim, P., Blacher, R. W., Fales, H. M., Riley, C. T., Klun, J. A., Ridgway, R. L., and Hayes, D. K. (1989). Identification of a neuropeptide hormone that regulates sex pheromone production in female moths. Science 244, 796-798.

Raina, A. K., and Kempe, T. G. (1990). A pentapeptide of the Cterminal sequence of PBAN with pheromonotropic activity. Insect Biochem. 20, 849-851.

Raina, A. K., and Kempe, T. G. (1992). Structure activity studies of PBAN of Helicoverpa zea (Lepidoptera: Noctuidae). Insect Biochem. Mol. Biol. 22 , 221-225.

Sato, Y., Ikeda, M., and Yamashita, O. (1994). Neurosecretory cells expressing the gene for common precursor for diapause hormone and pheromone biosynthesis-activating neuropeptide in the suboesophageal ganglion of the silkworm, Bombyx mori. Gen. Comp. Endocrinol. 96, 27-36.

Schoofs, L., Holman, G. M., Hayes, T. K., Kochansky, J. P., Nachman, R. J., and De Loof, A. (1990a). Locustatachykinin III and IV: two additional insect neuropeptides with homology to peptides of the vertebrate tachykinin family. Regul. Pept. 31, 199-212.

Schoofs, L., Holman, G. M., Hayes, T. K., Nachman, R. J., and De Loof, A. (1990b). Isolation, Identification and synthesis of locustamyotropin II, an additional neuropeptide of Locusta migratoria: member of the cephalomyotropic peptide family. Insect Biochem. 20, 479-484.

Schoofs, L., Holman, G. M., Hayes, T. K., Nachman, R. J., and De Loof, A. (1991). Isolation, primary structure, and synthesis of locustapyrokinin: a myotropic peptide of Locusta migratoria. Gen. Comp. Endocrinol. 81, 97-104.

Sun, J. S., Zhang, T. Y., Zhang, Q. R. and $\mathrm{Xu}, \mathrm{W} . \mathrm{H}$. (2003). Effect of the brain and suboesophageal ganglion on pupal development in Helicoverpa armigera through regulation of FXPRLamide neuropeptides. Regul. Pept. 116, 163-171.

Suwan, S., Isobe, M., Yamashita, O., Minakata, H., and Imai, K. (1994). Silkworm diapause hormone, structure-activity relationships indispensable role of Cterminal amide. Insect Biochem. Mol. Biol. 24, 1001-1007.

Tillman, J. A., Seybold, S. J., Jurenka, R. A., and Blomquist, G. J. (1999). Insect pheromones - an overview of biosynthesis and endocrine regulation. Insect Biochem. Mol. Biol. 29, 481-514.

Tips, A., Schoofs, L., Paemen, L. Ma, M., Blackburn, M., Raina A., and Loof, A. D. (1993). Colocalization of locustamyotropinand pheromone biosynthesis activating neuropeptide-like immunoreactivity in the central nervous system of five insect species. Comp. Biochem. Physiol. A Comp. Physiol. 106, 195-207.

Uehara, H., Senoh, Y., Yoneda, K., Kato, Y., and Shiomi, K. (2011). An FXPRLamide neuropeptide induces seasonal reproductive polyphenism underlying a life-history tradeoff in the tussock moth. PLoS ONE 6, e24213. doi:10.1371/journal.pone.0024213

Verleyen, P., Clynen, E., Huybrechts, J., Van Lommel, A., Vanden Bosch, L., 
De Loof, A., Zdarek, J., and Schoofs, L. (2004). Fraenkel's pupariation factor identified at last. Dev. Biol. 273, 38-47.

Wei, Z.-J., Hong, G.-Y., Jinag, S.-T., Tong, Z.-X., and Lu, C. (2008). Characters and expression of the gene encoding DH, PBAN and other FXPRLamide family neuropeptides in Antheraea pernyi. J. Appl. Entomol. 132, 59-67.

$\mathrm{Xu}$, W., Sato, Y., and Yamashita, O. (1999). Molecular characterization of the cDNA encoding diapause hormone and pheromone biosynthesis activating neuropeptide in Bombyx mandarina. Nihon Sanshigaku Zasshi 68, 373-379.
$\mathrm{Xu}, \mathrm{W} . \mathrm{H}$., and Denlinger, D. L. (2003). Molecular characterization of prothoracicotropic hormone and diapause hormone in Heliothis virescens during diapause, and a new role for diapause hormone. Insect Mol. Biol. 12, 509-516.

Zdarek, J., Nachman, R. J., and Hayes, T. K. (1997). Insect neuropeptides of the pyrokinin/PBAN family accelerate pupariation in the fleshfly (Sarcophaga bullata) larvae. Ann. N. Y. Acad. Sci. 814, 67-72.

Zhang, T. Y., Sun, J. S., Liu, W. Y., Kang, L., Shen, J. L., and $\mathrm{Xu}, \mathrm{W}$. H. (2005). Structural characterization and transcriptional regulation of the gene encoding diapause hormone and pheromone biosynthesis activating neuropeptide in the cotton bollworm, Helicoverpa armigera. Biochim. Biophys. Acta 1728, 44-52.

Zheng, L., Lytle, C., Njauw, C. N., Altstein, M., and Martins-Green, M. (2007). Cloning and characterization of the pheromone biosynthesis activating neuropeptide receptor gene in Spodoptera littoralis larvae. Gene 393, 20-30.

Conflict of Interest Statement: The authors declare that the research was conducted in the absence of any commercial or financial relationships that could be construed as a potential conflict of interest.
Received: 21 November 2011; accepted: 09 February 2012; published online: 24 February 2012.

Citation: Choi M-Y and Vander Meer $R K$ (2012) Molecular structure and diversity of PBAN/pyrokinin family peptides in ants. Front. Endocrin. 3:32. doi: 10.3389/fendo.2012.00032

This article was submitted to Frontiers in Experimental Endocrinology, a specialty of Frontiers in Endocrinology.

Copyright $\odot 2012$ Choi and Vander Meer. This is an open-access article distributed under the terms of the Creative Commons Attribution Non Commercial License, which permits non-commercial use, distribution, and reproduction in other forums, provided the original authors and source are credited. 